\title{
Increased Risk of Unfavorable Metabolic Outcome during Short-Term Follow-Up in Subjects with Nonfunctioning Adrenal Adenomas
}

\author{
S. Yener ${ }^{a} \quad$ S. Ertilav ${ }^{a} \quad$ M. Secil ${ }^{b} \quad$ B. Akincia T. Demir $^{a} \quad$ L. Kebapcilar ${ }^{a} \quad$ S. Yesil ${ }^{a}$ \\ ${ }^{a}$ Division of Endocrinology and Metabolism and ${ }^{b}$ Department of Radiology, School of Medicine, Dokuz Eylul \\ University, Izmir, Turkey
}

\section{Key Words}

Adrenal adenoma $\cdot$ Metabolic outcome $\cdot$ Follow-up

\begin{abstract}
Objective: To demonstrate long-term changes in the prevalence of several types of metabolic derangements in subjects with nonfunctioning adrenal adenomas. Subjects and Methods: 273 subjects with adrenal adenomas, including 231 with nonfunctioning adenoma and 42 with subclinical Cushing's syndrome (sCS), were evaluated with respect to anthropometric and laboratory characteristics and prevalence of type 2 diabetes mellitus (T2DM), hypertension, dyslipidemia, metabolic syndrome (MS), prediabetes and cardiovascular disease (CVD). Median duration was 24 months. Follow-up data of 114 participants with nonfunctioning adrenal adenomas are also presented while those of 117 were missing. Follow-up data regarding changes in anthropometric and laboratory parameters and prevalence rates of metabolic disturbances were obtained from the medical records. Results: The prevalence rates for both patients with nonfunctioning adenoma and sCS were: dyslipidemia: 161 (59\%), hypertension: 147 (54\%), MS: 128 (47\%), prediabetes: 62 (23\%), T2DM: 49 (18\%), and CVD: 21 (8\%). Hypertension and CVD were prevalent in subjects with sCS compared to participants with nonfunctioning adenoma. In follow-up, body mass index $(p=0.005)$, systolic blood pressure $(p<0.001)$, waist circumference $(p=0.005)$, homeostasis model assessment $(p=0.046)$, high-sensitivity C-reactive protein $(p=$
\end{abstract}

\section{KARGER}

Fax +4161306 1234

E-Mail karger@karger.ch

www.karger.com
(C) 2012 S. Karger AG, Basel

$1011-7571 / 12 / 0215-0429 \$ 38.00 / 0$

Accessible online at:

www.karger.com/mpp
$0.023)$, total cholesterol $(p<0.001)$ and low-density lipoprotein cholesterol $(p<0.001)$ and prevalence of hypertension $(p<0.001)$, dyslipidemia $(p<0.001)$, prediabetes $(p<0.001)$ and MS $(p<0.01)$ significantly increased in subjects with nonfunctioning adenoma. Conclusion: The data showed that nonfunctioning adrenal adenomas were associated with the development or deterioration of atherosclerotic risk factors. Therefore, follow-up and management strategies should be developed to decrease atherosclerotic morbidity in those individuals.

Copyright $\odot 2012$ S. Karger AG, Basel

\section{Introduction}

In the last decade, several studies have shown an association between adrenal adenomas and metabolic problems [1-5]. However, it remains unclear whether aging and increased insulin resistance could be associated with the development of adrenal cortical adenomas or whether adrenal adenomas alone could be responsible for the occurrence of metabolic problems. Following the demonstration of a wide variety of cortisol secretion in adrenal adenomas, subclinical Cushing's syndrome (sCS) was defined and studies showed that it was associated with disturbances in metabolic parameters [6, 7]. However, it was also demonstrated that several anthropometric and laboratory parameters were also disturbed even in subjects with nonfunctioning adrenal adenomas $[4,8]$. Despite the 
limited data regarding cortisol secretion dynamics, it was suggested that nonfunctioning adrenal adenomas might feature a milder form of cortisol autonomy [1-8].

Endogenous hypercortisolemia is associated with several atherosclerotic risk factors [9], with the frequency and severity of the metabolic derangements associated with the degree of autonomous cortisol secretion, from the increased prevalence of devastating disturbances in Cushing's syndrome to the milder forms of atherosclerotic risk factors in sCS and nonfunctioning adenomas. Despite the current knowledge regarding metabolic problems in subjects with nonfunctioning adrenal adenomas, the variety and frequency of those disturbances have not been studied in a large series. Moreover, follow-up data regarding the development or deterioration of metabolic problems in subjects with nonfunctioning adrenal adenomas is also lacking. In this study, we sought to demonstrate the prevalence of several cardiovascular risk factors in subjects with nonfunctioning adrenal adenomas at baseline and after 24 months' follow-up.

\section{Subjects and Methods}

This study was conducted at the Division of Endocrinology and Metabolism, Dokuz Eylul University, with the approval of the Ethics Committee of Dokuz Eylul University.

\section{Participants}

The records of 356 subjects who were referred to our institute with incidentally discovered adrenal tumors from 2002 to 2009 were reviewed. Subjects with clinically overt hormone hypersecretion (pheochromocytoma: $\mathrm{n}=20$, Cushing's syndrome: $\mathrm{n}=15$, primary hyperaldosteronism: $\mathrm{n}=14$, adrenal cysts and myelolipomas: $\mathrm{n}=15$, adrenal metastasis: $\mathrm{n}=15$, and missing data: $\mathrm{n}=$ 4) were excluded. Upon admission, the anthropometric and metabolic parameters of the remaining 273 participants were measured and the prevalence of several atherosclerotic risk factors was investigated. Due to the missing data or patient refusal the remaining 83 participants were not evaluated.

Of the 273 participants, the follow-up data of 114 participants with nonfunctioning adrenal adenomas were evaluated. Median duration was 24 months (6-132). Follow-up data regarding changes in anthropometric and laboratory parameters and prevalence rates of metabolic disturbances were obtained from medical records. Diabetes was considered present in any subject previously diagnosed with diabetes and currently using diabetes medication. In subjects without diabetes, diagnosis was established according to the diagnostic criteria of the American Diabetes Association [10]. Prediabetes was defined as impaired fasting glucose (fasting glucose $\geq 100 \mathrm{mg} / \mathrm{dl}$ ) or impaired glucose tolerance (2-hour glucose in 75 -gram oral glucose tolerance test $\geq 140 \mathrm{mg} / \mathrm{dl}$ ) [10]. Hypertension was considered present in subjects previously diagnosed with hypertension and currently using antihypertensive medication. In subjects without hypertension, diagnosis was es- tablished on the basis of systolic blood pressure $\geq 140 \mathrm{~mm} \mathrm{Hg}$ or diastolic blood pressure $\geq 90 \mathrm{~mm} \mathrm{Hg}$. Dyslipidemia was considered present in subjects previously diagnosed with dyslipidemia and currently using antihyperlipidemic medication. In subjects without dyslipidemia, diagnosis was established on the basis of total cholesterol $\geq 200 \mathrm{mg} / \mathrm{dl}$ and low-density lipoprotein cholesterol (LDL-C $\geq 130 \mathrm{mg} / \mathrm{dl}$ or the presence of isolated hypertriglyceridemia ( $\geq 200 \mathrm{mg} / \mathrm{dl}$ ) [11]. Cardiovascular disease was established by a history or development of unstable angina pectoris, non-ST elevated myocardial infarction, ST-elevated myocardial infarction, angiographically defined coronary artery plaques, coronary artery bypass graft surgery, radiologically defined peripheral artery or cerebrovascular disease or revascularization procedure, or stroke. Metabolic syndrome was established on the basis of three or more of the following signs: waist circumference $\geq 102 \mathrm{~cm}$ in men and $\geq 88 \mathrm{~cm}$ in women; serum triglyceride level $\geq 150 \mathrm{mg} / \mathrm{dl}$; high-density lipoprotein cholesterol (HDL-C) $<40 \mathrm{mg} / \mathrm{dl}$ in men and $<50 \mathrm{mg} / \mathrm{dl}$ in women; blood pressure $\geq 130 / 85 \mathrm{~mm} \mathrm{Hg}$; fasting glucose $\geq 110 \mathrm{mg} / \mathrm{dl}$ [11].

\section{Radiological Evaluation}

A computed tomography (CT) scan was performed for the initial radiological examination. Radiological follow-up included $\mathrm{CT}$ and/or magnetic resonance imaging (MRI) at 6 and 12 months and annually in subsequent visits. Malignancy was excluded if the following criteria were met for the CT: a homogeneous, regular shape with well-defined margins; attenuation value of 10 or less Hounsfield units on unenhanced CT scan; fewer Hounsfield units on enhanced CT scan; tumor diameter $<40 \mathrm{~mm}$. MRI was performed when CT scan failed to confirm the diagnosis. Additionally, MRI was preferred in cases with a history of hypersensitivity to nonionic iodinated contrast medium or a history of impaired renal function.

\section{Hormonal Evaluation}

Hormonal evaluation was performed at presentation, 6 months after the initial visit and annually in subsequent visits and included 8.00 a.m. cortisol, dehydroepiandrosterone sulfate (DHEAS), adrenocorticotrophic hormone (ACTH) and in hypertensive subjects plasma renin activity and serum aldosterone evaluation. Subsequently, urinary free cortisol (normal range $<110 \mu \mathrm{g} /$ day), urinary normetanephrine (normal range: $88-444 \mu \mathrm{g} /$ day) and urinary metanephrine (normal range: $52-341 \mu \mathrm{g} /$ day) were measured and overnight 1-mg dexamethasone suppression test (DST) was performed.

The suppression in overnight DST was considered to be adequate when morning cortisol fell below $1.8 \mu \mathrm{g} / \mathrm{dl}$. When postDST cortisol was over $1.8 \mu \mathrm{g} / \mathrm{dl}$, a 2-day 2-mg DST involving the administration of $0.5 \mathrm{mg}$ oral dexamethasone given every $6 \mathrm{~h}$ for $48 \mathrm{~h}$ was performed. In subjects with nonsuppressed cortisol levels, diurnal rhythm of cortisol was also evaluated (normal: midnight cortisol $<7.5 \mu \mathrm{g} / \mathrm{dl}$ ); sCS was defined as post-DST cortisol $>1.8 \mu \mathrm{g} / \mathrm{dl}$ with at least one of the following conditions positive: ACTH $<5 \mathrm{pg} / \mathrm{ml}$, urinary free cortisol $>110 \mu \mathrm{g} /$ day or midnight cortisol $>7.5 \mu \mathrm{g} / \mathrm{dl}$. Urinary cortisol and midnight cortisol were not measured in follow-up visits unless post-DST cortisol $>1.8 \mu \mathrm{g} / \mathrm{dl}$. Patients with suppressed post-DST cortisol levels were accepted as having nonfunctional adenoma if they additionally had at least one of the following criteria: morning DHEAS levels $\geq 40 \mu \mathrm{g} / \mathrm{dl}$; nonsuppressed plasma corticotro- 
phin $(\geq 5 \mathrm{pg} / \mathrm{ml})$; urinary free cortisol $<110 \mu \mathrm{g} /$ day or midnight cortisol.

Pheochromocytoma was defined as elevated levels of urinary normetanephrine and/or metanephrine. Primary hyperaldosteronism was screened for in hypertensive subjects with aldosterone/plasma renin activity ratio. In subjects with aldosterone/ plasma renin activity ratio $>25$, saline infusion test was performed.

\section{Anthropometric Measures}

Anthropometric and laboratory assessments were performed at presentation and annually in subsequent visits. Height, weight and waist circumference were measured and body mass index (BMI) was calculated. Blood pressure was measured using a sphygmomanometer after 5 min of rest in a sitting position.

\section{Laboratory Assessment}

After fasting overnight, a blood sample was withdrawn to measure plasma glucose, insulin, uric acid, high-sensitivity C-reactive protein (hsCRP), fibrinogen, total cholesterol, HDL-C and triglyceride levels. LDL-C was calculated. In nondiabetic subjects with plasma glucose $\geq 100 \mathrm{mg} / \mathrm{dl}$, 75 -gram oral glucose tolerance test was performed. Uric acid, glucose, triglycerides, total cholesterol and HDL-C levels were assessed using commercially available in vitro tests on Roche/Hitachi D/P Modular System Autoanalyzer (Roche Diagnostics, Basel, Switzerland). Insulin was measured using chemiluminescence enzyme immunoassay kit (Immunolite, Diagnostic Products Corp., Los Angeles, Calif., USA). Plasma fibrinogen was analyzed according to the Clauss method. Urine free cortisol and metanephrines were measured by high performance liquid chromatography (Agilent Technologies, Santa Clara, Calif., USA).

\section{Statistical Analysis}

Statistical analysis was performed with SPSS 15.0. Results were presented as means $\pm \mathrm{SD}$ or median (range). Independent samples $t$ test or Mann-Whitney $U$ test was applied for continuous variables; $\chi^{2}$ test was used for the comparison of dichotomous variables. Wilcoxon test was preferred for the comparison of related continuous variables and McNemar's test was applied to related dichotomous variables. A p value $<0.05$ was accepted to be statistically significant.

\section{Results}

The prevalence of metabolic disturbances in the patients with nonfunctioning adenomas and CS is shown in figure 1. Dyslipidemia (59.2\%), hypertension (54.3\%) and metabolic syndrome were the most frequent disturbances. Baseline characteristics of subjects with nonfunctioning adrenal adenomas and sCS are shown in table 1. Age, gender and BMI were similar for patients with nonfunctioning adenoma and sCS. Median tumor diameter was significantly elevated in the sCS group [20 (7-60) $\mathrm{mm}$ vs. $27.5(10-60) \mathrm{mm}, \mathrm{p}<0.001)]$.

Follow-Up in Nonfunctioning Adrenal Adenomas
The distribution of metabolic disturbances in subjects with nonfunctioning adenomas and sCS is given in table 1. Fibrinogen levels were significantly elevated. Prevalence of hypertension and cardiovascular events was significantly higher in the sCS group while the remaining parameters were comparable.

During follow-up, 114 participants with nonfunctioning adenoma were evaluated. The median duration of follow-up was 24 months (range: 6-132). The variation of several anthropometric and laboratory parameters is given in table 2. During follow-up, BMI, waist circumference, systolic blood pressure, homeostasis model assessment, hsCRP, total cholesterol and LDL-C levels significantly increased and morning DHEAS level significantly decreased. The frequency of developing type 2 diabetes mellitus was: $\mathrm{n}=2(1.8 \%)$, cardiovascular disease: $\mathrm{n}=4$ (3.5\%), metabolic syndrome: $\mathrm{n}=8(7.5 \%)$, hypertension: $\mathrm{n}=12(10.5 \%)$, dyslipidemia: $\mathrm{n}=27(23.7 \%)$, and prediabetes: $\mathrm{n}=40$ (34.5\%). Baseline and follow-up prevalence of metabolic problems is shown in figure 2 . The prevalence increase in hypertension $(p<0.001)$, dyslipidemia $(p<0.001)$, prediabetes $(p<0.001)$ and metabolic syndrome $(\mathrm{p}<0.01)$ was significant.

Direct logistic regression was performed to assess the impact of a number of factors on the development of hypertension, dyslipidemia, prediabetes and metabolic syndrome. The model contained age, gender, follow-up duration, adenoma diameter at follow-up and change in BMI as independent variables. None of these factors was found to have a significant effect on the development of metabolic disturbances.

\section{Discussion}

In this study, we showed that subjects with adrenal adenomas also had several metabolic problems. Dyslipidemia, hypertension and metabolic syndrome affected almost half of the participants. We also confirmed that sCS was associated with increased cardiovascular risk in terms of higher hypertension and cardiovascular disease prevalence and elevated fibrinogen levels. Data regarding cardiovascular disease risk in nonfunctional adrenal adenoma was not satisfactory. There are few studies with a small number of participants that evaluated specific markers such as certain adipocytokines or echocardiography findings as predictors of cardiovascular risk $[8,12]$. In the present study, the prevalence of type 2 diabetes, prediabetes and metabolic syndrome was comparable to that in gender, age and BMI-matched subjects with sCS. 
Table 1. Anthropometric and laboratory findings and prevalence of metabolic derangements at admission in participants with sCS and nonfunctioning adrenal adenoma

\begin{tabular}{lcccc}
\hline & $\begin{array}{l}\text { NFA } \\
(\mathrm{n}=231)\end{array}$ & $\begin{array}{l}\mathrm{sCS} \\
(\mathrm{n}=42)\end{array}$ & $\begin{array}{l}\text { Reference } \\
\text { ranges }\end{array}$ & $\mathrm{p}$ \\
\hline Age & $55.9 \pm 12.3$ & $58.8 \pm 10.4$ & - & $\mathrm{NS}$ \\
Gender, F/M & $168 / 63$ & $34 / 8$ & - & $\mathrm{NS}$ \\
BMI, $\mathrm{kg} / \mathrm{m}^{2}$ & $28.6 \pm 4.6$ & $29.5 \pm 4.9$ & - & $\mathrm{NS}$ \\
Tumor diameter & $20(7-60)$ & $27.5(10-60)$ & - & $<0.001$ \\
Diabetes, \% & 18.7 & 16.6 & - & $\mathrm{NS}$ \\
Hypertension, \% & 51.7 & 68.2 & - & 0.061 \\
Prediabetes, \% & 22.9 & 24.3 & - & $\mathrm{N}$ \\
Hyperlidemia, \% & 59.1 & 58.9 & - & $\mathrm{NS}$ \\
Cardiovascular event, \% & 6.7 & 19.5 & - & 0.016 \\
Metabolic syndrome, \% & 45.9 & 52.6 & - & $\mathrm{NS}$ \\
Uric acid, mg/dl & $4.7 \pm 1.3$ & $5.4 \pm 3.7$ & $3.5-7.2$ & $\mathrm{NS}$ \\
Fibrinogen, $\mathrm{g} / \mathrm{l}$ & $4.4 \pm 1.0$ & $5.2 \pm 0.86$ & $1.75-4.0$ & 0.020 \\
hsCRP, mg/l & $3.6 \pm 2.9$ & $4.1 \pm 3.4$ & $0.1-8.2$ & $\mathrm{NS}$ \\
Morning cortisol, $\mu \mathrm{g} / \mathrm{dl}$ & $14.0 \pm 5.7$ & $17.3 \pm 5.4$ & $5.0-25.0$ & 0.002 \\
Post-DST cortisol, $\mu \mathrm{g} / \mathrm{dl}$ & $1.4 \pm 0.65$ & $5.4 \pm 5.9$ & - & $<0.001$ \\
Urinary cortisol, $\mu \mathrm{g} / \mathrm{day}$ & $42.1 \pm 27.5$ & $120.5 \pm 106.5$ & $<110$ & $<0.001$ \\
Morning ACTH, $\mathrm{pg} / \mathrm{ml}$ & $16.3 \pm 8.3$ & $9.8 \pm 4.6$ & $0-46.0$ & $<0.001$ \\
Midnight cortisol, $\mu \mathrm{g} / \mathrm{dl}$ & $4.8 \pm 1.6$ & $9.9 \pm 7.4$ & - & 0.026 \\
Morning DHEAS, $\mu \mathrm{g} / \mathrm{dl}$ & $90.8 \pm 80.4$ & $55.7 \pm 61.2$ & $80.0-560.0$ & 0.012 \\
\hline
\end{tabular}

NFA = Nonfunctioning adenoma .

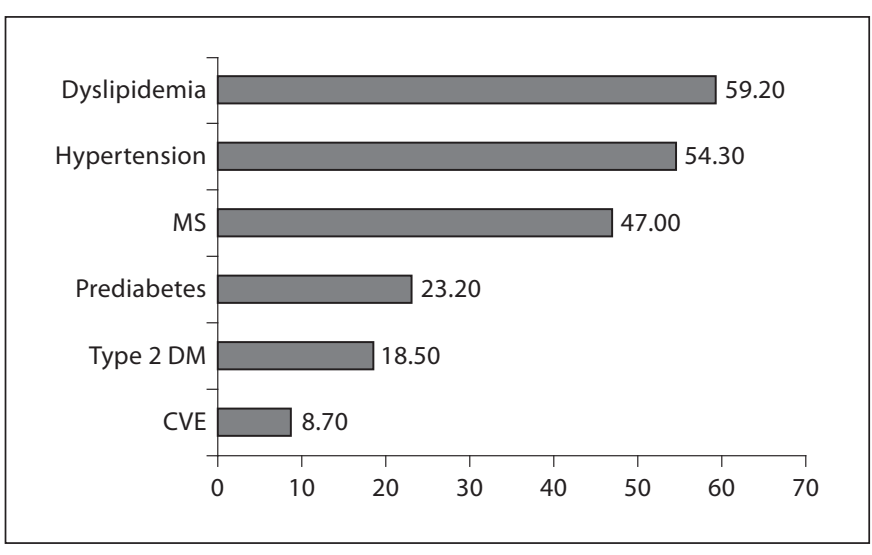

Fig. 1. Frequency of metabolic disturbances in subjects with adrenal adenomas $(\mathrm{n}=273)$. $\mathrm{MS}=$ Metabolic syndrome; $\mathrm{DM}=$ diabetes mellitus; CVE = cardiovascular event.

This finding may provide evidence to support the role of nonfunctioning adrenal adenoma in the development of metabolic derangements.

Long-term management of adrenal adenoma in terms of atherosclerotic risk factors is controversial. The current data on this issue has been derived from a few studies that have shown the beneficial effects of adrenalectomy on metabolic parameters in subjects with sCS $[13,14]$. Recently, Sereg et al. [15] showed that adrenalectomy failed to improve adverse metabolic profile in subjects with nonfunctioning adrenal adenomas. The question whether a nonfunctional adrenal adenoma could be associated with future metabolic problems and atherosclerotic risk has not been answered in the present study, we demonstrated that subjects with nonfunctioning adenoma had several disturbances in both anthropometric and laboratory indices during 24 months' follow-up. Additionally, a significant increase in the prevalence of dyslipidemia, hypertension, prediabetes and metabolic syndrome was observed. The equivocal part of the association between nonfunctioning adrenal adenoma and metabolic syndrome is whether adrenal adenoma could directly cause metabolic derangements. It has been suggested that adrenal adenomas may be characterized by alterations in cortisol secretion rates such that the degree of autonomous cortisol production is a continuum from subtle cortisol autonomy of nonfunctioning adenomas below the detection threshold of routine laboratory investigations to more pathological secretion that could be seen in sCS $[1$, 16]. This subtle but continuous cortisol autonomy could 
Table 2. Anthropometric and laboratory changes during follow-up in nonfunctioning adrenal adenomas $(\mathrm{n}=114)$

\begin{tabular}{|c|c|c|c|c|}
\hline & Baseline & $\begin{array}{l}\text { After } \\
\text { follow-up }\end{array}$ & $\begin{array}{l}\text { Reference } \\
\text { ranges }\end{array}$ & $\mathrm{p}$ \\
\hline $\mathrm{BMI}, \mathrm{kg} / \mathrm{m}^{2}$ & $29.2 \pm 4.6$ & $29.7 \pm 4.7$ & - & 0.005 \\
\hline Waist circumference, $\mathrm{cm}$ & $93.3 \pm 9.3$ & $96.1 \pm 9.9$ & - & 0.005 \\
\hline Systolic BP, mm Hg & $127.5 \pm 18.6$ & $138.2 \pm 21.1$ & - & $<0.001$ \\
\hline Diastolic BP, mm Hg & $80.1 \pm 10.9$ & $82.2 \pm 12.6$ & - & NS \\
\hline Fasting plasma glucose, $\mathrm{mg} / \mathrm{dl}$ & $100.5 \pm 21.1$ & $107.4 \pm 18.8$ & $70.0-100.0$ & $<0.001$ \\
\hline Fasting insulin, $\mu \mathrm{IU} / \mathrm{ml}$ & $6.1 \pm 1.21$ & $10.1 \pm 1.9$ & $6.0-28.4$ & 0.109 \\
\hline HOMA & $2.2 \pm 1.8$ & $3.1 \pm 3.1$ & - & 0.046 \\
\hline Uric acid, mg/dl & $4.7 \pm 1.2$ & $4.8 \pm 1.4$ & $3.5-7.2$ & NS \\
\hline Fibrinogen, g/l & $4.4 \pm 1.1$ & $4.7 \pm 1.1$ & $1.75-4.0$ & 0.065 \\
\hline hsCRP, mg/l & $3.3 \pm 2.6$ & $4.9 \pm 4.5$ & $0.1-8.2$ & 0.023 \\
\hline Total cholesterol, mg/dl & $212.6 \pm 39.2$ & $229.2 \pm 41.8$ & $140-200$ & $<0.001$ \\
\hline LDL-C, mg/dl & $132.3 \pm 33.2$ & $146.3 \pm 32.6$ & $100-130$ & $<0.001$ \\
\hline $\mathrm{HDL}-\mathrm{C}, \mathrm{mg} / \mathrm{dl}$ & $52.6 \pm 13.7$ & $53.0 \pm 12.4$ & $35-55$ & NS \\
\hline Triglyceride, mg/dl & $141.3 \pm 75.9$ & $150.0 \pm 84.3$ & $30-190$ & NS \\
\hline Morning cortisol, $\mu \mathrm{g} / \mathrm{dl}$ & $14.2 \pm 5.8$ & $13.7 \pm 5.4$ & $5.0-25.0$ & NS \\
\hline Post-DST cortisol, $\mu \mathrm{g} / \mathrm{dl}$ & $1.3 \pm 0.5$ & $1.3 \pm 0.4$ & - & NS \\
\hline Morning ACTH, pg/ml & $17.3 \pm 8.3$ & $16.1 \pm 8.7$ & $0-46.0$ & NS \\
\hline Morning DHEAS, $\mu \mathrm{g} / \mathrm{dl}$ & $104.1 \pm 94.0$ & $79.7 \pm 66.9$ & $80.0-560.0$ & $<0.001$ \\
\hline
\end{tabular}

HOMA = Homeostasis model assessment.

be responsible for the unfavorable outcome in metabolic parameters. There is a considerable amount of literature on HPA axis activation and increased risk of cardiovascular disease. A study from Caerphilly showed a correlation of cortisol and testosterone as a predictor of incident ischemic heart disease [17]. Several studies have suggested that plasma cortisol levels correlate with the degree of coronary artery disease $[18,19]$. It has also been shown that morning cortisol levels are associated with components of metabolic syndrome [20,21]. The mechanism of glucocorticoid-induced metabolic disturbances is complicated. Glucocorticoids increase the turnover between stored energy and freely available fuel for mitochondrial oxidation [9]. They both impair insulin-dependent glucose uptake in the periphery and also enhance gluconeogenesis in the liver [22]. Furthermore, they may increase vagal stimulation of insulin secretion with their central action [23]. It has been shown that a positive association was present between skeletal muscle myoblast expression of the glucocorticoid receptor and levels of insulin resistance, BMI, percent body fat and blood pressure [24]. Elevated concentrations of cortisol and increased tissue sensitivity to glucocorticoids are likely to increase glucocorticoid hormone action and metabolic syndrome risk.

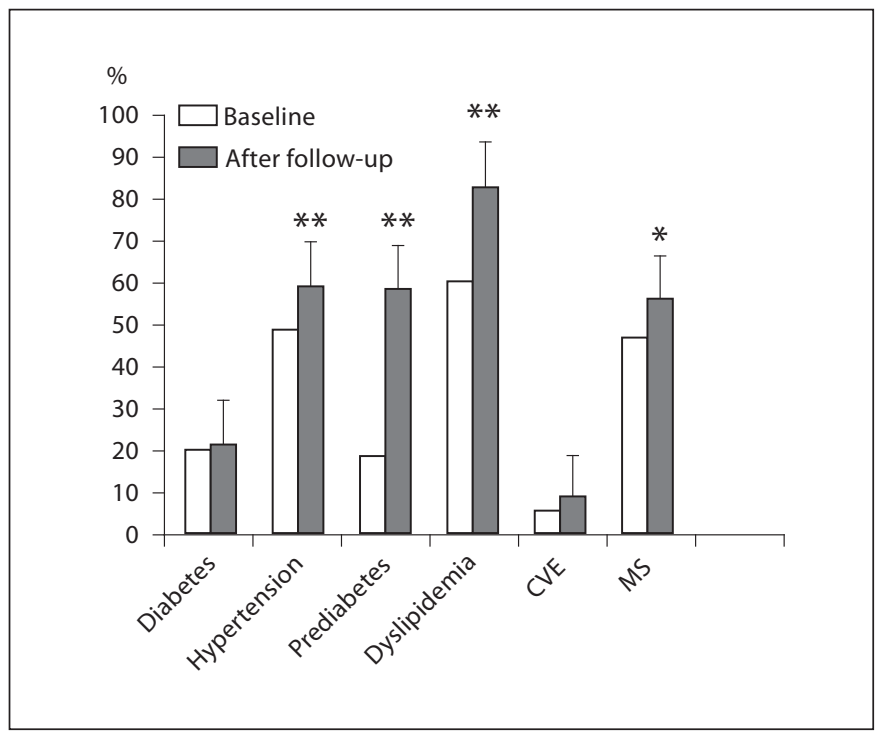

Fig. 2. Prevalence of metabolic derangements at baseline and at the end of follow-up in participants with nonfunctioning adrenal adenoma $(n=114)$. Median follow-up duration was $24(6-132)$ months. $\mathrm{CVE}=$ Cardiovascular event; $\mathrm{MS}=$ metabolic syndrome. ${ }^{*} \mathrm{p}<0.01$ versus baseline; ${ }^{* *} \mathrm{p}<0.001$ versus baseline. McNemar test was applied. 
A major limitation of this study is the lack of a control group. More appropriate suggestions regarding the relationship between adrenal adenoma and the development of metabolic problems could have been made if a positive control group (i.e., sCS) or a negative control group (subjects without adrenal adenoma) had been included in the follow-up study. Additionally, adrenal adenomas are usually detected in middle-aged and elderly subjects with a wide range of complaints and comorbidities who are more likely to develop metabolic and cardiovascular derangements. This referral bias should also be taken into account while interpreting the results of our study.

\section{Conclusion}

Our results demonstrated that nonfunctioning adrenal adenoma was associated with metabolic derangements and was also involved in the development or deterioration of atherosclerotic risk factors. Subtle cortisol autonomy of clinically silent adenomas could be implicated in the development of unfavorable metabolic outcome. The question whether adrenalectomy or treatment of metabolic consequences would be beneficial should be addressed in new studies.

\section{References}

1 Rossi R, Tauchmanova L, Luciano A, Di Martino M, Battista C, Del Viscovo L, Nuzzo V, Lombardi G: Subclinical Cushing’s syndrome in patients with adrenal incidentaloma: clinical and biochemical features. J Clin Endocrinol Metab 2000;85:1440-1448.

-2 Tauchmanova L, Rossi R, Biondi B, Pulcrano M, Nuzzo V, Palmieri EA, Fazio S, Lombardi G: Patients with subclinical Cushing's syndrome due to adrenal adenoma have increased cardiovascular risk. J Clin Endocrinol Metab 2002;87:4872-4878.

$>3$ Terzolo M, Bovio S, Pia A, Conton PA, Reimondo G, Dall'Asta C, Bemporad D, Angeli A, Opocher G, Mannelli M, Ambrosi B, Mantero F: Midnight serum cortisol as a marker of increased cardiovascular risk in patients with a clinically inapparent adrenal adenoma. Eur J Endocrinol 2005;153:307315.

4 Terzolo M, Pia A, Ali A, Osella G, Reimondo G, Bovio S, Daffara F, Procopio M, Paccotti P, Borretta G, Angeli A: Adrenal incidentaloma: a new cause of the metabolic syndrome? J Clin Endocrinol Metab 2002;87:998-1003.

$>5$ Vierhapper H, Heinze G, Gessl A, Exner M: Adrenocortical tumors: prevalence of impaired glucose tolerance and of 'paradoxical rise' of cortisol during an oral glucose tolerance test. Exp Clin Endocrinol Diabetes 2003; 111:415-420.

6 Terzolo M, Bovio S, Reimondo G, Pia A, Osella G, Borretta G, Angeli A: Subclinical Cushing's syndrome in adrenal incidentalomas. Endocrinol Metab Clin North Am 2005;34:423-439, x.

7 Terzolo M, Reimondo G, Bovio S, Angeli A: Subclinical Cushing's syndrome. Pituitary 2004;7:217-223.

8 Ermetici F, Dall'Asta C, Malavazos AE, Coman C, Morricone L, Montericcio V, Ambrosi B: Echocardiographic alterations in patients with non-functioning adrenal inci- dentaloma. J Endocrinol Invest 2008;31: 573-577.

-9 Walker BR: Glucocorticoids and cardiovascular disease. Eur J Endocrinol 2007;157: 545-559.

10 Standards of medical care in diabetes -2009 Diabetes Care 2009;32(suppl 1):S13-S61.

11 Third Report of the National Cholesterol Education Program (NCEP) Expert Panel on Detection, Evaluation, and Treatment of High Blood Cholesterol in Adults (Adult Treatment Panel III) final report. Circulation 2002; 106:3143-3421.

12 Ermetici F, Malavazos AE, Corbetta S, Morricone L, Dall'Asta C, Corsi MM, Ambrosi B: Adipokine levels and cardiovascular risk in patients with adrenal incidentaloma. Metabolism 2007;56:686-692.

13 Erbil Y, Ademoglu E, Ozbey N, Barbaros U, Yanik BT, Salmaslioglu A, Bozbora A, Ozarmagan S: Evaluation of the cardiovascular risk in patients with subclinical Cushing syndrome before and after surgery. World J Surg 2006;30:1665-1671.

14 Midorikawa S, Sanada H, Hashimoto S, Suzuki T, Watanabe T: The improvement of insulin resistance in patients with adrenal incidentaloma by surgical resection. Clin Endocrinol (Oxf) 2001;54:797-804.

15 Sereg M, Szappanos A, Toke J, Karlinger K, Feldman K, Kaszper E, Varga I, Glaz E, Racz $\mathrm{K}$, Toth M: Atherosclerotic risk factors and complications in patients with non-functioning adrenal adenomas treated with or without adrenalectomy: a long-term follow-up study. Eur J Endocrinol 2009;160:647-655.

16 Sartorio A, Conti A, Ferrero S, Giambona S, Re T, Passini E, Ambrosi B: Evaluation of markers of bone and collagen turnover in patients with active and preclinical Cushing's syndrome and in patients with adrenal incidentaloma. Eur J Endocrinol 1998;138:146152.
17 Smith GD, Ben-Shlomo Y, Beswick A, Yarnell J, Lightman S, Elwood P: Cortisol, testosterone, and coronary heart disease: prospective evidence from the Caerphilly study. Circulation 2005;112:332-340.

18 Koertge J, Al-Khalili F, Ahnve S, Janszky I, Svane B, Schenck-Gustafsson K: Cortisol and vital exhaustion in relation to significant coronary artery stenosis in middleaged women with acute coronary syndrome. Psychoneuroendocrinology 2002;27:893906.

19 Varma VK, Rushing JT, Ettinger WH Jr: High density lipoprotein cholesterol is associated with serum cortisol in older people. J Am Geriatr Soc 1995;43:1345-1349.

20 Phillips DI, Barker DJ, Fall CH, Seckl JR, Whorwood CB, Wood PJ, Walker BR: Elevated plasma cortisol concentrations: a link between low birth weight and the insulin resistance syndrome? J Clin Endocrinol Metab 1998;83:757-760.

21 Ward AM, Fall CH, Stein CE, Kumaran K, Veena SR, Wood PJ, Syddall HE, Phillips DI: Cortisol and the metabolic syndrome in South Asians. Clin Endocrinol (Oxf) 2003; 58:500-505.

22 Rizza RA, Mandarino LJ, Gerich JE: Cortisol-induced insulin resistance in man: impaired suppression of glucose production and stimulation of glucose utilization due to a postreceptor detect of insulin action. J Clin Endocrinol Metab 1982;54:131-138.

23 Stubbs M, York DA: Central glucocorticoid regulation of parasympathetic drive to pancreatic B-cells in the obese $\mathrm{fa} / \mathrm{fa}$ rat. Int $\mathrm{J}$ Obes 1991; 15:547-553.

24 Whorwood CB, Donovan SJ, Flanagan D, Phillips DI, Byrne CD: Increased glucocorticoid receptor expression in human skeletal muscle cells may contribute to the pathogenesis of the metabolic syndrome. Diabetes 2002;51:1066-1075. 